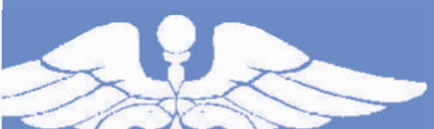

ISSN: 2782-7550 (Print) ISSN: 2782-7542 (Online)
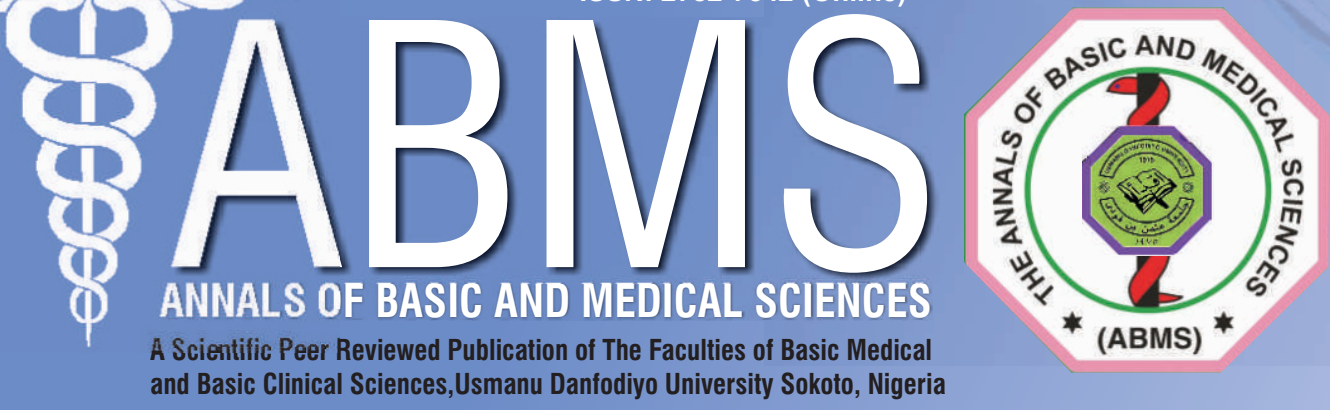

and Basic Clinical Sciences,Usmanu Danfodiyo University Sokoto, Nigeria
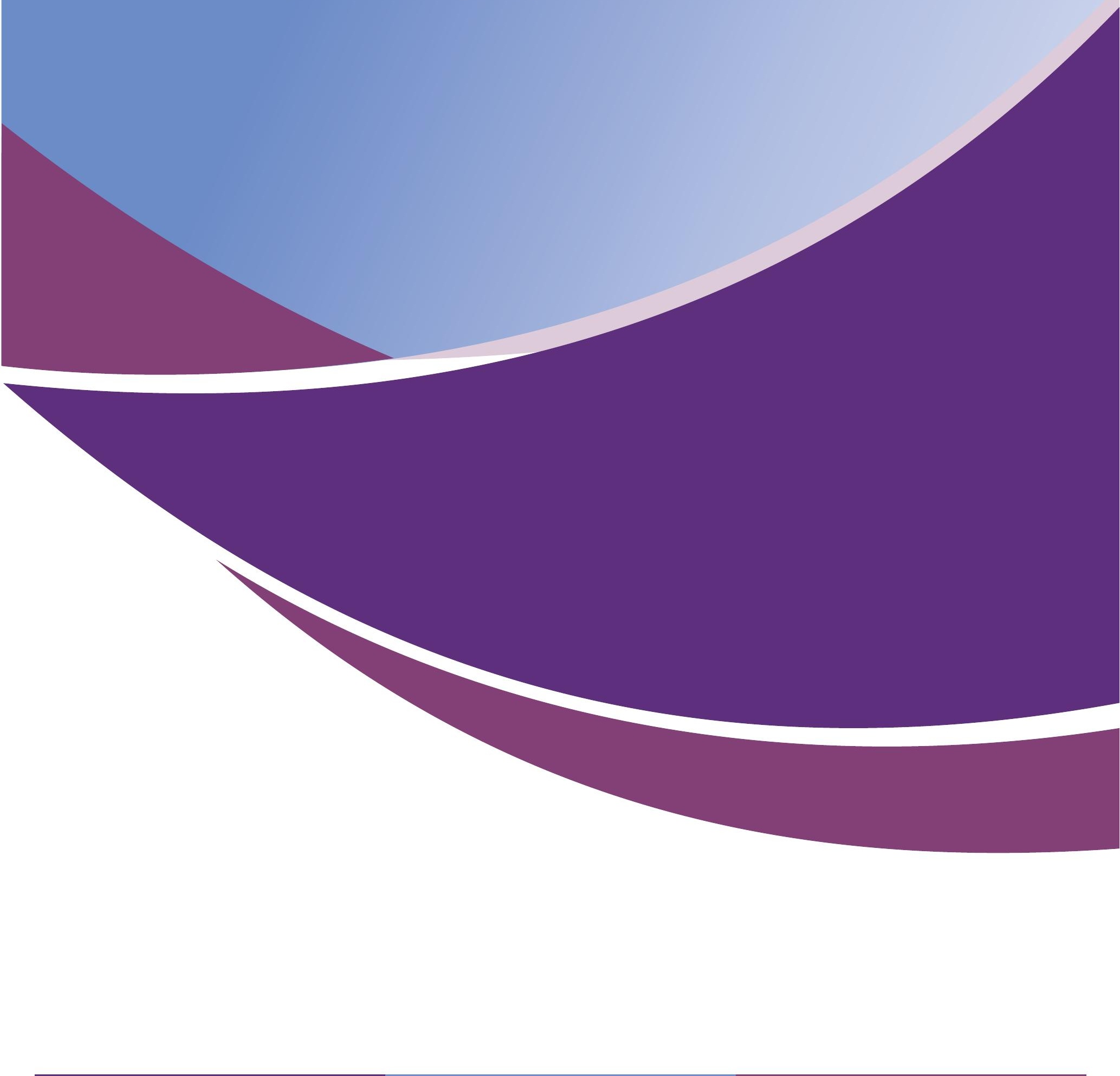

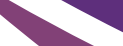
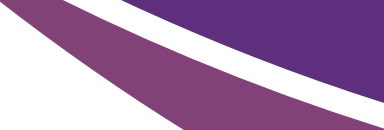


\title{
Influence of Camel Milk on the Antibacterial Activity of Ciprofloxacin
}

\section{Abdulhamid Imam Tanko*, Abdulgafar Olayiwola Jimoh², Muhammad Tukur Umar², Shuaibu Abdullahi Hudu ${ }^{3}$.}

\author{
${ }^{1}$ Department of Paediatrics, Specialist Hospital, Sokoto. \\ ${ }^{2}$ Department of Pharmacology and Therapeutics, Faculty of Basic Clinical Sciences, College of Health Sciences, \\ Usmanu Danfodiyo University, Sokoto. \\ ${ }^{3}$ Department of Medical Microbiology, Faculty of Basic Clinical Sciences, College of Health Sciences, \\ Usmanu Danfodiyo University, Sokoto.
}

\begin{abstract}
Background: Despite the availability of more researched and formulated orthodox medicines, traditional medicines remain the main source of therapy for the majority of people worldwide with some patrons concurrently using both forms unaware of the unwanted effects that may occur. Camel milk is often used alone or in combination with other orthodox medications to treat diseases. The study aimed to investigate
\end{abstract} the influence of camel milk on the antibacterial activity of ciprofloxacin.

Materials and methods: The in vitro antibacterial activity of camel milk escalating doses $(30 \mu \mathrm{L}, 100 \mu \mathrm{L}$ and $300 \mu \mathrm{L})$ alone and in combination with Ciprofloxacin escalating doses $(2 \mathrm{mcg}, 5 \mathrm{mcg}, 15 \mathrm{mcg})$ against some clinical bacterial isolates (Pseudomonas aeruginosa, Escherichia coli, Staphylococcus aureus, Serratia marcescens) was determined using the Agar-well diffusion method.

Result: Camel milk escalating doses alone showed dose-dependent antibacterial effect against all the test bacteria. However, combinations of the camel milk escalating doses and ciprofloxacin escalating doses respectively produced an antagonistic effect against all the test organisms.

Conclusion: Fresh camel milk possesses antibacterial activity against Pseudomonas aeruginosa, Escherichia coli, Serratia marcescens and Staphylococcus aureus but is not recommended for combination with ciprofloxacin to treat infections caused by the above organisms.

Keywords: Antibacterial, Ciprofloxacin, Camel milk, Pseudomonas aeruginosa, Escherichia coli, Staphylococcus aureus, Serratia.

Corresponding author:

Abdulhamid Imam Tanko

Department of Paediatrics, Specialist Hospital, Sokoto

Phone:

Email: abdulhamidimamtanko@gmail.com.

\section{Introduction}

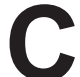
amel milk has been used as medicine since antiquity (1). In Northern Nigeria, the practice of the use of camel milk is becoming more interesting; due to the folkloric claims on its therapeutic potentials against a wide range of diseases (2). In Asia and Africa, camel milk is used to treat some diseases such as gastrointestinal disorders, sugar diseases, food allergy, psoriasis, hepatitis $C$ and B, autism and tuberculosis. Mostly consumed fresh by pastoralist before treatment (2). Camel milk contains low cholesterol, low sugar, high minerals (sodium, potassium, iron, copper, zinc and magnesium), high vitamin $\mathrm{C}$, protective proteins like lactoferrin, lactoperoxidase, immunoglobulins, and lysozyme (3). It has been suggested that high concentrations of lactoferrin and lysozyme are responsible for its antimicrobial activity (4). Lactoferrin can act as either a bacteriostatic and/or bactericidal agent (5). The composition of camel milk depends on many factors affecting the camel milk such as season, feeding conditions, and water availability (6).

Ciprofloxacin is the most potent first-generation fluoroquinolones active against a broad range of bacteria (7). It is highly active against Escherichia. coli and moderately active against Staphylococcus. aureus (8). It works by inhibiting the enzyme bacterial DNA gyrase. (7). Though ciprofloxacin is rapidly absorbed orally, the presence of food delays its absorption (9). Ciprofloxacin has an effective first-pass metabolism, a bioavailability of $60-80 \%$ and elimination half-life of $3-5$ hours (10). It is excreted primarily in urine, both by glomerular filtration and tubular secretion (10). Some of the side effects of ciprofloxacin include; nausea, vomiting and hypersensitivity reaction (7). It is used in the treatment of urinary tract infection, typhoid fever and gonorrhea (8). Infectious diseases are among the ten top leading causes of death in Nigeria, with malaria and lower respiratory tract infections top on the list(11). Antimicrobial resistance is the ability of the microorganisms to resist the effects of drugs that once could successfully eradicate them (12). It occurs when microorganisms including bacteria, viruses, fungi, and parasites adapt and grow in the presence of medications that once kill them. It threatens the effective prevention and treatment of an ever-increasing range of infection caused by bacteria, viruses, fungi, and parasite (13). The causes of antimicrobial resistance in developing countries such as Nigeria may be rooted in practices of health care professionals and patients' behavior towards the use of antimicrobials as well as supply chains of antimicrobials in the population (14). These factors may include inappropriate prescription practices, inadequate patient education, limited diagnostic facilities, unauthorized sale of antimicrobials, 
lack of appropriate functioning drug regulatory mechanisms, and non-human use of antimicrobials such as in animal production. There is a need to address the context and focus on the root causes specific to this part of the world (14). Combination therapy is a treatment modality often employed to treat dreadful diseases to achieve synergy and prevent or delay the emergence of antimicrobial resistance (15).

Food-Drug interaction is the interaction between natural products and drugs (16). It is a common hidden problem encountered in clinical practice (16). This kind of interaction is based on the same pharmacokinetic and pharmacodynamics principles as drug-drug interactions. A lot of fruits and berries have been shown to contain substances that affect drug-metabolizing enzymes (16). Food-drug interactions can change the bioavailability of a drug by a chemical reaction such as chelation or by a physiological response to food intake which include changes in gastric acidity, bile secretion, and gastrointestinal motility. Food-drug interactions that only affect the rate of drug absorption are common, but are of less clinical importance (17). It was reported that "Despite the development of more researched and formulated orthodox medicines, traditional medicines continue to be well patronized for persons across the world with some patrons concurrently using both forms, oblivious of the unwanted effects that may occur" (18). The rising incidence of multidrug resistance amongst pathogenic microbes has further necessitated the need to search for newer antibiotic sources (19). A study of antimicrobial activity of camel milk has been carried out in Asia (20). However, to the best of our knowledge, the local study of the antimicrobial activity of camel milk and the influence of its co-administration with ciprofloxacin has not been carried out in Nigeria. The aim of this study was therefore to evaluate the in vitro antibacterial action of Camel milk and its influence on the antibacterial activity of ciprofloxacin when used concurrently on selected bacterial isolates.

\section{Materials and methods}

Drugs

Ciprofloxacin tablet (gecip Tablet, Geneith PHARM LIMITED, 500mg equivalent to ciprofloxacin hydrochloride USP: NAFDAC.Reg.No:B4-5856, mfg.Lic. No.:SU20160088, Batch No: 191103, mfg Date: 11/2019, Expiry Date: 11/2022).

\section{Bacterial isolates}

Bacterial isolates of Staphylococcus aureus, Serratia marcescens, Pseudomonas aeruginosa and Escherichia coli were kindly sourced from the Department of Medical Microbiology, Faculty of Basic Clinical Sciences, College of Health Sciences, Usmanu Danfodiyo University, Sokoto (UDUS)

\section{Collection of camel milk}

Camel milk was collected every day from a camel herd in Sokoto (Kware Local government), Nigeria. The milk was collected from a healthy camel (4 years old) by hand milking in sterile screw bottles and kept in boxes containing ice packs until transported to the Pharmacology Laboratory, UDUS, where it was kept refrigerated.

Preparation of stock concentration of ciprofloxacin A single $500 \mathrm{mg}$ tablet of ciprofloxacin was first ground to powder using pestle and mortar. It was then dissolved in $1000 \mathrm{ml}$ of distilled water to get a concentration of $500 \mathrm{mg}$ per litre and a stock concentration of $0.5 \mathrm{mg} / \mathrm{ml}$ $(500 \mathrm{mcg} / \mathrm{ml})$.

\section{Preparation of culture media}

Muller Hilton agar and broth were used to culture the organisms and conduct the experiments. Muller Hilton agar was prepared according to the manufacturer's instructions. Briefly, 38 grams of the media was suspended in $1000 \mathrm{ml}$ of distilled water. It was then heated to boiling to dissolve the media completely for 1 minute. It was then autoclaved at $121^{\circ} \mathrm{C}$ for 15 minutes and cooled to room temperature. The cooled Mueller Hilton agar was then poured into sterile petri dishes on a level, horizontal surface to give uniform depth. The plates were then stored at $8^{\circ} \mathrm{C}$ before inoculation. Mueller Hilton broth preparation was also carried out according to manufacturer's instructions, i.e. $21 \mathrm{~g}$ of dehydrated powder was suspended in 1 liter of distilled water. The mixture was then mixed well and dissolved by heating with frequent agitation. It was boiled for 1 minute until complete dissolution. It was then dispensed into sterile test tubes; the mouth of the tubes were then cotton plugged. The test tubes with the media were then sterilized by autoclaving at $121^{\circ} \mathrm{C}$ for 15 minutes.

\section{Transfer of inoculum into broth tube}

The wire inoculating loop was first sterilized by passing it at an angle through the flame of the Bunsen burner until the entire length of the wire became glowing red from the heat. The loop was then allowed to cool for a few seconds to avoid killing the inoculums. The loop was then inserted into the inoculum tube and a loop full of inoculum was removed. The mouth of the tube was then flamed and recapped and the culture tube was placed back on the test tube rack. A tube of sterile Mueller Hilton broth was then picked and capped (cotton plug) gently removed and the mouth of the tube was flamed. The loop was then inserted into the sterile Mueller Hilton broth to inoculate it by gently moving the loop back and forth to disperse the cells. The loop was then removed from the tube and immediately the mouth of the tube was flamed again and the cotton plug/ cap was replaced and the tube was hung on the test tube rack. The wire loop was then sterilized. The procedure was repeated for the four organisms each in a separate test tube. The inoculated culture together with control (containing distilled water) were then immediately incubated at $37^{\circ} \mathrm{C}$ for $48 \mathrm{hrs}$. Growth of organisms was noted in all four tubes (they became turbid) except in the 
the control tube.

\section{Adjustment of liquid bacterial culture to McFarland standard}

All the four strains of the bacterial isolates after overnight incubation became turbid. This turbidity was then adjusted to 0.5 McFarland turbidity standard with an optical density comparable to density of bacterial suspension with a $1.5 \times 108$ colony-forming unit (CFU/ml) using a spectrophotometer at $630 \mathrm{~nm}$. About $1 \mathrm{ml}$ of bacterial broth suspension was pipetted using a sterile syringe and was placed in an empty sterile test tube, and about $9 \mathrm{ml}$ of sterile Mueller Hilton broth was then added in the same test tube and mixed by shaking. The turbidity was compared by holding the bacterial sample and McFarland standard tubes up against black and white bars printed on the enclosed card. The turbidity of the log growth of the bacterial suspension was adjusted with the addition of more sterile broth to match the turbidity of the standard.

Evaluation of the in vitro synergistic action of camel milk and ciprofloxacin against Staphylococcus aureus, Serratia marcescens, Pseudomonas aeruginosa and Escherichia coli.

Based on the protocol stated by Yassin 2015 (20) with some modifications, Briefly about 12 disc plates were prepared for the experiment (3 plates for an individual organism). Four wells were created on each plate using a sterile cork borer. Disc 1, 2, 3, were Staphylococcus aureus discs, disc 4, 5, 6 were Escherichia coli discs, disc 7, 8, 9, were Serratia discs and disc 10, 11, 12, were Pseudomonas aeruginosa discs. About $100 \mu \mathrm{L}$ of prepared inoculums of each of the test organism were pipetted using a sterile micropipette. This was then spread on an already punctured Mueller Hilton agar medium and spread uniformly on the surface of the media using a sterile glass rod.

On discs 1, 4, 7 and 10, 3 graded $(30 \mu \mathrm{L}, 100 \mu \mathrm{L}$, $300 \mu \mathrm{L})$ doses of camel milk were instilled into the 3 wells using sterile micropipette. The fourth well received $10 \mu \mathrm{L}$ of distilled water and served as control. On disc 2, 5, 8, and 11, 3 graded doses of ciprofloxacin [2mcg $(4 \mu \mathrm{L}), 5 \mathrm{mcg}(10 \mu \mathrm{L}), 15 \mathrm{mcg}(30 \mu \mathrm{L})]$ were installed into 3 wells using a sterile micropipette. The fourth well in each of the four plates served as control and received $10 \mu \mathrm{L}$ of distilled water. On disc 3, 6, 9, and 12,3 graded doses of ciprofloxacin +3 graded doses of camel milk were installed into 3 wells (i.e., well 1; 2 mcg Cipro (ciprofloxacin) $+30 \mu \mathrm{L}$ CM (camel milk), in well 2; $5 \mathrm{mcg}$ Cipro $+100 \mu \mathrm{L} \mathrm{CM}$, in well 3; $15 \mathrm{mcg}$ Cipro $+300 \mu \mathrm{L} \mathrm{CM})$. The fourth well of each disc was left as control and received $10 \mu \mathrm{L}$ of distilled water. After incubation at $37^{\circ} \mathrm{C}$ for $48 \mathrm{~h}$, the different levels of the zones of inhibition were measured with the help of an antibiotic zone reader.

\section{Statistical}

The data was analyzed using Microsoft Excel version
10 and the results were presented in tables.

\section{Results}

Table 1: Antibacterial effect of camel milk on Staphylococcus aureus, Escherichia coli, Pseudomonas aeruginosa and Serratia marcescens.

Fresh Camel milk graded doses alone showed inhibition of bacterial growth against all of the test organisms except for the $30 \mu \mathrm{L}$ dose $(0 \mathrm{~mm} \mathrm{ZI)} \mathrm{(Table} \mathrm{1).}$

\begin{tabular}{lll}
\hline Organism & Camel milk $(\mu \mathrm{L})$ & Zone of inhibition $(\mathrm{mm})$ \\
\hline Staphylococcus aureus & 300 & 13.5 \\
& 100 & 10.0 \\
& 30 & 0.0 \\
Escherichia coli & 300 & 14.5 \\
& 100 & 9.5 \\
& 30 & 0.0 \\
Pseudomonas aeruginosa & 300 & 13.5 \\
& 100 & 10 \\
Serratia marcescens & 30 & 0.0 \\
& 300 & 14.5 \\
& 100 & 12.5 \\
& 30 & 0.0 \\
\hline
\end{tabular}

$\mu \mathrm{L}=$ microlitre $\mathrm{mm}=$ millimeter, $\mathrm{mcg}=$ micrograms.

Table 2: Antibacterial effect of ciprofloxacin on Staphylococcus aureus, Escherichia coli, Pseudomonas aeruginosa and Serratia marcescens.

\begin{tabular}{lll}
\hline Organism & Ciprofloxacin $(\mathrm{mcg})$ & Zone of inhibition $(\mathrm{mm})$ \\
\hline Staphylococcus aureus & 15 & 42.5 \\
& 5 & 37.5 \\
Escherichia coli & 2 & 36.5 \\
& 15 & 19.5 \\
Pseudomonas aeruginosa & 5 & 14.0 \\
& 2 & 9.5 \\
Serratia marcescens & 5 & 40 \\
& 2 & 39 \\
& 15 & 34 \\
& 5 & 40.5 \\
& 2 & 35.5 \\
\hline
\end{tabular}

$\mu \mathrm{L}=$ microlitre $\mathrm{mm}=$ millimeter, $\mathrm{mcg}=$ micrograms.

Table 3. Antibacterial effect of concurrent use of Camel milk with Ciprofloxacin on Staphylococcus aureus, Escherichia coli, Pseudomonas aeruginosa and Serratia marcescens.

Combination of camel milk with ciprofloxacin produced greater inhibition of bacterial growth against all of the test organisms except for Escherichia coli when compared to camel milk alone or ciprofloxacin alone (Table 3).

\begin{tabular}{lllll}
\hline \multicolumn{5}{l}{ Zone of Inhibition $(\mathrm{mm})$} \\
\hline Drugs & $\begin{array}{l}\text { Staphylococ } \\
\text { cus aureus }\end{array}$ & $\begin{array}{l}\text { Escherichia } \\
\text { coli }\end{array}$ & $\begin{array}{l}\text { Pseudomonas } \\
\text { aeruginosa }\end{array}$ & Serratia \\
\hline $\mathrm{CM}(300 \mu \mathrm{L})+\mathrm{CIPRO}(15 \mathrm{mcg})$ & 41.5 & 9.5 & 41.5 & 39.5 \\
$\mathrm{CM}(100 \mu \mathrm{L})+\mathrm{CIPRO}(5 \mathrm{mcg})$ & 35.0 & 7.5 & 37.5 & 35.0 \\
$\mathrm{CM}(30 \mu \mathrm{L})+\mathrm{CIPRO}(2 \mathrm{mcg})$ & 33.0 & 6.5 & 30.0 & 31.5 \\
\hline
\end{tabular}

$\mathrm{Zl}=$ Zone of inhibition, $\mathrm{CM}=$ Camel milk, CIPRO=Ciprofloxacin, $\mathrm{mm}=$ millimeter, $\mathrm{mcg}=$ micrograms, $\mu \mathrm{L}=$ microliter.

\section{Discussion}

In this study, camel milk graded doses alone showed antibacterial effect at doses of $100 \mu \mathrm{L}$ and $300 \mu \mathrm{L}$, but no activity at $30 \mu \mathrm{L}$ doses (0mm zone of inhibition) against all the four test organisms, with no significant difference in the zone of inhibition of all the organisms. Also ciprofloxacin graded doses alone showed antibacterial activity against all the test organisms. However, 
the antibacterial activity of ciprofloxacin was less against Escherichia coli when compared to other organisms. In this study, we also found out that a combination of camel milk and ciprofloxacin in graded doses does not show greater activity/enhancement in bacterial growth inhibition (increase in diameter of zone of inhibition) in all test organisms. This does not agree with the finding on the antibacterial activity of camel milk with ciprofloxacin on Staphylococcus aureus and Escherichia coli as reported by Yassin 2015 (20) which showed synergistic action. This finding is the first reported finding on the local antibacterial antagonistic action of camel milk with an antibiotic. Possible mechanisms of the antagonistic effect of the camel milk with ciprofloxacin include; 1. Formation of slightly soluble complex with metal iron contained in the milk which eventually leads to reduced bioavailability of ciprofloxacin through decrease absorption. 2. Increase in gastric $\mathrm{pH}$ by the camel milk which might have decrease the bioavailability of several nutrients, such as iron and vitamins contained in the milk which further favor iron-ciprofloxacin complexation (21). 3. Increased elimination rate of ciprofloxacin co-administered with the camel milk (22). The antagonistic action in our study may be also due to variation in the composition of camel milk which depends on the season, lactation period, feeding conditions, and water availability when compared to synergistic finding reported by Yassin 2015 (6). The antibacterial effect of the camel milk was probably due to high concentrations of Lactoferrin and Lysozyme(4). Lactoferrin acts as either a bacteriostatic and/or bactericidal agent (23). Lactoferrin is a nutrient found in the milk of humans and other mammals (24). It is an iron-binding protein that has important immunological properties, and is both antibacterial and antiviral (24). It is found in biological fluids with a high concentration in mammalian milk. Depletion of iron by lactoferrin prevents bacterial growth. It has immunomodulatory and anti-inflammatory activity (25). Lysozyme is an enzyme found in secretions including saliva, human milk, and mucus, and has direct antimicrobial role through hydrolysis of cell wall peptidoglycan of bacteria, and modulates the host immune response to infection (26). Lactoperoxidase is an enzyme produced by mammary, salivary, and other mucosal glands that functions as a natural antibacterial agent (27). It belongs to the family of enzymes known as heme peroxidase (28).

\section{Conclusion and recommendations}

In conclusion, this study showed the antagonistic action of camel milk with ciprofloxacin on inhibition of bacterial growth for all the tested organisms. Therefore, combination therapy of camel milk with ciprofloxacin for treating diseases caused by the above-tested organisms is not recommended.

\section{Conflict of interest}

None declared

\section{References}

1. Pak V V, Khojimatov OK, Abdiniyazova GJ, Magay EB. Composition of camel milk and evaluation of food supply for camels in Uzbekistan. J Ethn Foods. 2019;6(20):1-8.

2. Kaskous S. Camel Milk Composition, Udder Health and Effect of Different Storage Times and Temperatures on Raw Milk Quality U. Asian Online J Publ Gr. 2019;6:172-81.

3. Yadav AK, Kumar R, Priyadarshini L, Singh J. Composition and medicinal properties of camel milk : A Review. 2015;34(2):83-91.

4. Al-Juboori AT, Mohammed M, Rashid J, Kurian J, El Refaey S. Nutritional and medicinal value of camel (Camelus dromedarius) milk. WIT Trans Ecol Environ. 2013;170:221-32.

5. Al-majali AM. Lactoferrin Concentration in Milk.pdf. Intern J Appl Res Vet Med. 2007;5(3):120-4.

6. Omer RH and Ahe. Chemical composition of camel's colostrum and milk in united arab emirates. J Agric Sci. 2008;16(1):127-33.

7. Sharma D, Patel RP, Zaidi STR, Camerino GM, Aldo B, Moraes LA. Interplay of the Quality of Ciprofloxacin and Antibiotic Resistance in Developing Countries. Front Pharmacol. 2017;8(546):1-7.

8. Tripathi K. Essentials of Medical Pharmacology. Seventh Edition. 2013. 636-637.

9. Sharma PC, Jain A, Jain S, Pahwa R, Yar MS. Ciprofloxacin: Review on developments in synthetic, analytical , and medicinal aspects. J Enzyme Inhib Med Chem. 2010;25(4):577-89.

10. Harder S, Fuhr U, Beermann D, Staib AH. Ciprofloxacin absorption in different regions of the human gastrointestinal tract . Investigations with the hf-capsule. Br J clin Pharmac. 1990;30:35-9.

11. Muhammad F, Abdulkareem JH, Chowdhury ABMA. Major Public Health Problems in Nigeria : A review. South East Asia J Public Heal. 2017;7(1):6-11.

12. WHO. WHO global report on traditional and complementary medicine 2019

13. Dadgostar P. Antimicrobial Resistance: Implications and Costs. È Dove Press journal Infection Drug Resist. 2019;12:3903-10.

14. Ayukekbong JA, Ntemgwa M, Atabe AN. The threat of antimicrobial resistance in developing countries : Causes and control strategies. Antimicrob Resist Infect Control. 2017;6(47):1-8.

15. Chou T. Drug Combination Studies and their Synergy Quantification using the Chou-Talalay Method. 2010;70(2):440-7.

16. Rabia Bushra, Nousheen Aslam AYK. Food-Drug Interactions. Oman Med J. 2011;26(2):77-83.

17. Byrne BE. Drug interactions : a review and update. Endod Top. 2003;4:9-21.

18. Ameade EPK, Ibrahim M, Ibrahim H-S, Habib RH, Gbedema SY. Concurrent Use of Herbal and Orthodox Medicines among Residents of Tamale, Northern Ghana, Who Patronize Hospitals and Herbal Clinics. Evidence-Based Complement Altern Med. 2018;1-8.

19. Doughari JH. Antimicrobial Activity of Tamarindus indica Linn. Trop J Pharm Res. 2006;5:597-603.

20. Yassin MH, Soliman MM, Mostafa SA, Ali HA. Antimicrobial Effects of Camel Milk against Some Bacterial Pathogens. J Food Nutr Res. 2015;3(3):162-8.

21. Panda V, Shinde P, Deora J, Gupta P. A comparative study of the antacid effect of some commonly consumed foods for hyperacidity in an artificial stomach model. Complement Ther Med. 2017;34:111-5.

22. Dey B, Katakam P, Assaleh FH, Rao B, Kumari S, Mitra A. In vitro - in vivo studies of the quantitative effect of calcium , multivitamins and milk on single dose ciprofloxacin bioavailability. J Pharm Anal [Internet]. 2015;5(6):389-95.

23. Al-majali Amzbiya-Hayn. Lactoferrin Concentration in Milk From Camels ( Camelus dromedarius ) With and Without Subclinical Mastitis. Intern J Appl Res Vet Med. 2007;5(3):120-4.

24. Kell DB, Heyden EL, Pretorius E. The Biology of Lactoferrin , an Iron-Binding Protein That Can Help Defend Against Viruses and Bacteria. Front Immunol. 2020;11(1221):1-15. 
Tanko et al... Influence of Camel Milk on the Antibacterial Activity of Ciprofloxacin

25. Siqueiros-cendón T, Arévalo-gallegos $\mathrm{S}$, Iglesias-figueroa BF Abril I. Immunomodulatory effects of lactoferrin. Acta Pharmacol Sin. 2014;35:557-66.

26. Ragland SA, Criss AK. From bacterial killing to immune modulation: Recent insights into the functions of lysozyme. PLOS Pathog. 2017;13(9):1-22.
27. Bafort F, Parisi O, Perraudin J, Jijakli MH. Mode of Action of Lactoperoxidase as Related to Its Antimicrobial Activity: A Review. Enzyme Res. 2014;1-13.

28. Magacz M, Karolina K, Sapa J, Krzy W. The Significance of Lactoperoxidase System in Oral Health: Application and Efficacy in Oral Hygiene Products. Int J Mol Sci. 2019;20(1443):1-31. 